\title{
Perceived naturalness and acceptance of genetically modified food
}

Citation for published version (APA):

Tenbült, P., de Vries, N. K., Dreezens, E. A. A., \& Martijn, C. (2005). Perceived naturalness and acceptance of genetically modified food. Appetite, 45(1), 47-50. https://doi.org/10.1016/j.appet.2005.03.004

Document status and date:

Published: 01/01/2005

DOI:

10.1016/j.appet.2005.03.004

Document Version:

Publisher's PDF, also known as Version of record

Document license:

Taverne

Please check the document version of this publication:

- A submitted manuscript is the version of the article upon submission and before peer-review. There can be important differences between the submitted version and the official published version of record.

People interested in the research are advised to contact the author for the final version of the publication, or visit the DOI to the publisher's website.

- The final author version and the galley proof are versions of the publication after peer review.

- The final published version features the final layout of the paper including the volume, issue and page numbers.

Link to publication

\footnotetext{
General rights rights.

- You may freely distribute the URL identifying the publication in the public portal. please follow below link for the End User Agreement:

www.umlib.nl/taverne-license

Take down policy

If you believe that this document breaches copyright please contact us at:

repository@maastrichtuniversity.nl

providing details and we will investigate your claim.
}

Copyright and moral rights for the publications made accessible in the public portal are retained by the authors and/or other copyright owners and it is a condition of accessing publications that users recognise and abide by the legal requirements associated with these

- Users may download and print one copy of any publication from the public portal for the purpose of private study or research.

- You may not further distribute the material or use it for any profit-making activity or commercial gain

If the publication is distributed under the terms of Article $25 \mathrm{fa}$ of the Dutch Copyright Act, indicated by the "Taverne" license above, 


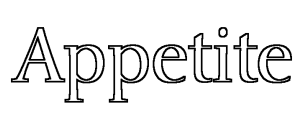

Appetite 45 (2005) 47-50

www.elsevier.com/locate/appet

Research Report

\title{
Perceived naturalness and acceptance of genetically modified food
}

\author{
Petra Tenbült ${ }^{\mathrm{a}, *}$, Nanne K. de Vries ${ }^{\mathrm{a}}$, Ellen Dreezens ${ }^{\mathrm{b}}$, Carolien Martijn ${ }^{\mathrm{b}}$ \\ ${ }^{a}$ Department of Health Education and Health Promotion, Maastricht University, P.O. Box 616, 6200 MD Maastricht, The Netherlands \\ ${ }^{\mathrm{b}}$ Department of Psychology, Maastricht University, P.O. Box 616, 6200 MD Maastricht, The Netherlands
}

Received 15 October 2004; received in revised form 1 December 2004; accepted 1 January 2005

\begin{abstract}
This study examines people's acceptance of genetically modified (GM) food. Results suggest that GM acceptance depends most on how natural the genetically modified product is perceived and not directly on how natural the non-GM product is seen. A GM product that is perceived as more natural is more likely to be accepted than a GM product that is perceived as less natural. The extent to which GM affects the perceived naturalness of a product partly depends on the kind of product.
\end{abstract}

(C) 2005 Elsevier Ltd. All rights reserved.

Keywords: Genetic modification; Acceptance; Naturalness

\section{Introduction}

More and more products are either genetically modified or organically grown. The change of hereditary material by transferring properties of one organism (e.g. plant, animal) into another organism is referred to as genetic modification (GM). With this technique, varieties of plants and animals can be created that are, for example, more resistant to herbicides or richer in vitamins. Opinions towards GM differ strongly and this issue is heavily debated. Grunert, Bredahl, and Scholderer (2003) showed that consumer attitudes are negative towards GM in food production. The authors suggest that the negative attitudes are embedded in a system of more general attitudes (e.g. towards nature). Dreezens, Martijn, Tenbült, Kok, and de Vries (2005) showed that specific values play a role in predicting participants' attitudes towards genetic modified foods. It appears that interpersonal differences are related to different attitudes towards GM. Other studies (Gamble, Muggleston, Hedderley, Parminter, \& Vaughan, 2000; Tenbült, de Vries, Dreezens, \& Martijn, unpublished manuscript) have also

\footnotetext{
* Corresponding author.

E-mail address: p.tenbult@gvo.unimaas.nl (P. Tenbült).
}

0195-6663/\$ - see front matter (C) 2005 Elsevier Ltd. All rights reserved. doi:10.1016/j.appet.2005.03.004 shown a negative attitude towards GM. Consumers reject it for ethical reasons. They are afraid of the long-term effects of consuming genetically modified foods; they believe that it will disadvantage developing countries or that it disturbs the ecological balance et cetera.

Acceptance of genetic modification in food production varies over different consumer categories. GM acceptance has been related to socio-demographic factors (Hossain, Onyango, Adelaja, Schilling, \& Hallman, 2002; Onyango, \& Nayga Jr., 2004), trust and confidence in science, government and biotechnology companies (Frewer, Howard, \& Shepherd, 1998; Hossain et al., 2002; Onyango et al., 2004), nature of the GM technology that has been used (Burton \& Pearse, 2003; Frewer et al., 1998; Onyango, \& Nayga Jr. 2004) and information provided about GM (Grunert et al., 2003).

Only a few studies relate GM acceptance to the type of food products. Research by Gamble et al. (2000) suggests that acceptance of genetic modification in foods is product-specific. The authors show that consumers are more interested in labels when they are purchasing a 'healthy' item for others, than when they want to buy a snack, like chocolate, for themselves. Consumers believed that the way tomatoes are produced is more important than, for example, the quality, taste and price of the product. Interestingly, this pattern is reversed when they are presented with chocolate biscuits. The authors suggest that the chocolate biscuits are already seen as being unhealthy, so consumers do not care whether the production technology is 
also regarded as unhealthy. Apparently, the basis for evaluations of products differs between product categories. Genetic modification can be a feature that influences this evaluation and it is therefore likely that acceptability of genetic modification depends on product categories.

In the study by Gamble et al. (2000), the perceived healthiness of products was investigated as the decisive characteristic. More in general, evaluations of products can also be determined by other criteria, for example, the extent to which a product is seen as less important or less necessary for people's diet or whether the product is seen as less natural or not. Rozin, Spranca, Krieger, Neuhaus, Sunllo, Swerdlin, \& Wood (2004) showed that people have a substantial preference for natural over processed or artificial products. When people are confronted with two products that are chemically identical, but one of the two is natural and the other is artificial, people prefer the natural one. If $\mathrm{GM}$ is perceived as an artificial procedure in food production, it follows that GM products are seen as less natural, and will therefore be less well accepted.

The present research aims to investigate whether GM acceptance is product-specific and whether the perceived naturalness, healthiness or necessity of the products determine the acceptability of genetic engineering in different product categories. We expect that the perceived naturalness rather than the perceived healthiness or perceived necessity of products influences GM acceptance and that differences between categories with regard to perceived naturalness account for differences in GM acceptance.

\section{Method}

Food products. In a pilot study, 10 participants were asked to generate food products that differed on two dimensions, 'healthiness' and 'necessity'. The participants were asked to name products that were healthy and necessary, healthy and not necessary, not healthy but necessary and not healthy and not necessary. They were also asked to underline the products that they thought were natural. Based on this pilot study, we chose the food products in each category that were generated most frequently (and at least by $50 \%$ of the respondents). These products were: 'butter', 'mars', 'tomato', 'crisps', 'fish fingers' and 'bread' (see Table 1).

Sample. One hundred and forty-four undergraduate students (114 women, 30 men) at the University of Maastricht participated in this study. The mean age of

Table 1

The chosen products (the underlined products were seen as natural by the subjects)

\begin{tabular}{lll}
\hline & Healthy & Not healthy \\
\hline Necessary & $\frac{\text { Tomato }}{\text { Bread }}$ & Butter \\
Not necessary & Fish fingers & $\begin{array}{l}\text { Crisps } \\
\text { Mars }\end{array}$ \\
\hline
\end{tabular}

the subjects was 19.80 years $(\mathrm{SD}=2.09$, range: $17-33)$. Before the start of a lecture, participants were asked to fill out a questionnaire. They were told that it contained some questions about genetically modified food products and that they would have the opportunity to fill it out during the break, or just after the lecture. About $50 \%$ of the undergraduates responded. The subjects participated on a fully voluntary basis and received no reward for their participation.

Questionnaire. Participants were asked to imagine each of the seven products one at a time and to answer three questions. These questions measured the extent to which the products were seen as being 'natural', necessary, 'healthy' (e.g. 'I believe bread is healthy') on a five-point scale ranging from 1 (totally disagree) to 5 (totally agree). Subsequently, participants were asked to imagine genetically modified variants of the products and three questions were posed. Two questions dealt with the acceptance of the just imagined genetic modified product (e.g. 'Eating this (GM) bread is morally wrong', and 'I have trust in this (GM) bread'); one question was about the extent to which the GM product was seen as unnatural (e.g. 'This (GM) bread is unnatural'). These questions were also rated on a five-point scale ranging from 1 (totally disagree) to 5 (totally agree). We did not measure perceived naturalness, healthiness or necessity of the GM food products.

\section{Results}

\section{'Necessary' and 'less necessary' category of products}

In the pilot study, 'tomato', 'butter' and 'bread' were classified as necessary (see Table 1). From now on we will refer to these products as the 'necessary' category of products. 'Fish fingers', 'crisps' and 'mars' will be referred to as 'less necessary'. The mean ratings of both categories of products were calculated for all further analyses.

\section{Product specificity}

The two categories were compared with regard to the perceived naturalness of the non-GM variant, the perceived unnaturalness of the GM variant and acceptance of the GM product. A paired samples $T$-test showed that the "necessary' category of products is perceived as being more natural than the 'less necessary' category of products $[t(143)=$ 23.24, $p<0.001]$. Besides this, paired samples $T$-tests also showed that in general for products in the 'necessary' category, it was more accepted when they were genetically modified than for products in the 'less necessary' category $[t(143)=2.05, p<0.05$ (for means see Table 2) $]$. No significant difference was found between the two categories with regard to GM unnaturalness. The 'necessary' category is perceived as being more natural in its original state, and is also more accepted when it is genetically modified 
Table 2

Means $(M)$ and standard deviations (SD) for GM acceptance and the perceived naturalness and GM unnaturalness, for the 'necessary' and 'less necessary' categories of products

\begin{tabular}{llll}
\hline & & $M$ & SD \\
\hline 'Necessary' category & Naturalness non-GM & 3.99 & 0.61 \\
& Unnaturalness GM & 2.53 & 1.00 \\
& Acceptance GM & 3.07 & 0.91 \\
'Less necessary' category & Naturalness non-GM & 2.11 & 0.67 \\
& Unnaturalness GM & 2.46 & 0.95 \\
& Acceptance GM & 3.01 & 0.86 \\
\hline
\end{tabular}

compared to the 'less necessary' category. Importantly, GM acceptance differs between the two categories.

\section{Correlations}

Correlations between the perceived naturalness and GM unnaturalness were positive for both categories (see Table 3). The more a product is perceived as natural, the more its GM form is seen as unnatural.

The perceived unnaturalness of the GM 'necessary' category and the GM 'less necessary' category correlated negatively with GM acceptance (see Table 3 ). So, the more unnatural the GM group is perceived, the less likely it is that GM will be accepted.

Only the perceived naturalness and necessity of the 'necessary' category correlated negatively with GM acceptance of the 'necessary' category [necessity, $r(144)=-0.202, p<0.05$; naturalness, $r(144)=-0.229$, $p<0.01]$. So, the more natural and the more necessary the 'necessary' category is perceived, the less likely GM acceptance will occur.

GM acceptance was regressed on perceived naturalness and GM unnaturalness for both categories. GM unnaturalness was a significant predictor of GM acceptance of the 'necessary' category of products $[\beta=0.51, p<0.001$, $F(1,142)=50.52, p<0.001]$. GM unnaturalness was also a significant predictor of GM acceptance of the 'less necessary' category of products $[\beta=0.39, p<0.001$, $F(1,142)=25.95, p<0.001]$. So, GM acceptance can be predicted by the perceived unnaturalness of the GM forms for both the 'necessary' and 'less necessary' categories of products. Perceived naturalness of the original products was a non-significant predictor in both cases. Thus, it may be suggested that the negative correlation between perceived naturalness and necessity with GM acceptance within the 'necessary' category is due to intercorrelations of these variables.

\section{Technology specificity}

Analysis of correlations between GM acceptances of different products showed very high correlations (all $R \mathrm{~s}$ above 0.73 ). Apparently, people who accept some products in GM form are also likely to accept other products in GM form more.

\section{Discussion}

GM acceptance depends on how natural the GM product is perceived. This can be influenced by the kind of product that is genetically modified and by interpersonal differences. The more a product is seen as natural from the start, the less genetic modification of that product will be accepted. People who are against genetic modification will show in general less GM acceptance.

The finding of Gamble et al. (2000) that the extent to which a product is seen as healthy determines the acceptance of genetic modification of that product is not supported by our data. Our data show that the extent to which a product is seen as natural or necessary has an effect on the acceptance of GM and, more importantly, that this is mediated by the perceived unnaturalness of the GM products. Products differ in perceived naturalness. When products are seen as necessary for people's diet, they will be perceived as more natural. When these 'necessary' products become genetically modified the respondents will see that product as more unnatural in its GM form and will therefore have more problems with accepting it. 'Less necessary' products are perceived as less natural from the start and will therefore loose relatively little 'perceived naturalness' when they are in GM form. These latter products are relatively more easily accepted. Our data show that the 'necessary' category of products is more accepted in GM form than the 'unnecessary' category of products. This difference is significant, but it is also very small. Although our data do not show a convincing difference in GM acceptance between the two categories of products, it appears that within both categories the more natural products are less accepted in GM form. It can be concluded that GM acceptance seems to differ between products to the extent

Table 3

Correlations of unnaturalness of GM products, necessity and naturalness of non-GM products and GM acceptance for the two categories

\begin{tabular}{|c|c|c|c|c|c|c|}
\hline & \multicolumn{3}{|c|}{ 'Necessary' category } & \multicolumn{3}{|c|}{ 'Less necessary' category } \\
\hline & Necessity & Naturalness & GM unnaturalness & Necessity & Naturalness & GM unnaturalness \\
\hline Naturalness & $0.373^{* *}$ & 1 & $0.354 * *$ & $0.368 * *$ & 1 & $0.529 * *$ \\
\hline GM unnaturalness & n.s. & $.354 * *$ & 1 & n.s. & $0.529 * *$ & 1 \\
\hline GM acceptance & $-0.202 *$ & $-0.229^{* *}$ & $-0.512^{* *}$ & n.s. & $-0.199 *$ & $-0.393^{* *}$ \\
\hline
\end{tabular}

$N=144 . * *$ Correlation is significant at the 0.001 level (two-tailed). *Correlation is significant at the 0.01 level (two-tailed). 
that they are seen as natural (or less unnatural) in their genetically modified form.

GM acceptance is also influenced by interpersonal differences. Our data show that people who do not accept one GM product are also not willing to accept another GM product. Apparently people who have a negative attitude towards GM believe that GM affects a product' naturalness to a great extent. Consequently these people find it harder to accept GM products in general.

We did not measure perceived healthiness or necessity of the GM food products. In a next study, we will measure this in order to see whether perceived healthiness or necessity of the GM food products predicts GM acceptance. Our subjects had to imagine food products. In a next study, we will confront our subjects with real food products and we will use conventional and manufactured products. Possibly, manufactured products are less accepted in GM form compared to conventional GM products because they are perceived as less natural, less necessary and less healthy from the start.

In this study, we divided our products in a 'necessary' and a 'less necessary' category. We also analysed our data in a 'healthy' versus 'less healthy' category and found similar results. It can be concluded that the extent to which a GM product is seen as natural determines to a great extent whether it will be accepted. Contrary to other research findings, we have not obtained convincing evidence that the way in which the non-GM product is perceived influences acceptance. Rather, it is the perception of the GM form that determines acceptance: the more a product loses its perceived naturalness when it is genetically modified, the less it will be accepted.

\section{References}

Burton, M., \& Pearse, D. (2003). Consumer attitudes towards genetic modification, functional foods, and microorganisms: A choice modeling experiment for beer. AgBioForum, 3, 14-19.

Dreezens, E., Martijn, C., Tenbült, P., Kok, G., \& de Vries, N. K. (2005). Food and values: An examination of values underlying attitudes toward genetically modified- and organically grown food products. Appetite 44, 115-122.

Frewer, L. J., Howard, C., \& Shepherd, R. (1998). The influence of initial attitudes on responses to communication about genetic engineering in food production. Agriculture and Human Values, 15, $15-30$.

Gamble, J., Muggleston, S., Hedderley, D., Parminter, T., \& Vaughan, G. (2000). Genetic engineering: The public's point of view. HortResearch NZ Client Report No. 2000/249. New Zealand: HortResearch NZ NZ.

Grunert, K. G., Bredahl, L., \& Scholderer, J. (2003). Four questions on European consumers' attitudes toward the use of genetic modification in food production. Innovative Food Science and Emerging Technologies, 4, 435-445.

Hossain, F., Onyango, B., Adelaja, A., Schilling, B., \& Hallman, W. (2002). Consumer acceptance of food biotechnology: Willingness to buy genetically modified food products. Agricultural and Resource Economics Review, 31, 260.

Onyango, B., Nayga, Jr., R.M. (2004). Consumer acceptance of nutritionally enhanced genetically modified food. Journal of Agricultural and Resource Economics, 29, 567-583.

Rozin, P., Spranca, M., Krieger, Z., Neuhaus, R., Surillo, D., Swerdlin, A., $\&$ Wood, K. (2005). Preference for natural: Instrumental and ideational/ moral motivations, and the contrast between foods and medicines. Appetite, 43, 147-154.

Tenbült, P., de Vries, N.K., Dreezens, E., \& Martijn, C. (unpublished manuscript). Can we always express what we like and why? Implicit and explicit attitudes towards new food technologies. 